\title{
Early identification of anthracycline cardiomyopathy: possibilities and implications
}

\author{
Frances A Bu'Lock, Martin G Mott, Anthony Oakhill, Robin P Martin
}

\begin{abstract}
The number of survivors of childhood cancer affected by anthracycline cardiomyopathy is steadily increasing, despite efforts to limit cardiotoxicity by dose restriction. Cardiac function was evaluated prospectively in 125 children during treatment to attempt to identify individual susceptibilities to cardiotoxicity and hence any potential for treatment modification.

Left ventricular shortening fraction was used as an index of cardiotoxicity. Shortening fraction declined as cumulative anthracycline dose increased, at an average rate of $1 \%$ per $100 \mathrm{mg} / \mathrm{m}^{2}$. Six patients $(5 \%)$ developed heart failure. Twenty four patients $(19 \%)$ had abnormal shortening fraction $(<30 \%)$ by the end of treatment, and their rate of fall of shortening fraction was significantly steeper throughout treatment than in patients finishing with normal function (shortening fraction $\geqslant 30 \%$ ). This differential susceptibility to cardiotoxicity was apparent from very early in treatment, interquartile ranges of the two shortening fraction groups separating at doses $>200 \mathrm{mg} / \mathrm{m}^{2}$.

Patients at high risk of risk of important anthracycline cardiotoxicity may be identifiable early in treatment by regular and careful monitoring of shortening fraction. However, frequent assessment is required and this has significant resource implications.

(Arch Dis Child 1996;75:416-422)
\end{abstract}

Keywords: cardiomyopathy, anthracycline, monitoring, echocardiography.

Bristol Royal Hospital for Sick Children, Department of Paediatric Cardiology FA Bu'Lock RP Martin

Department of Paediatric Oncology MG Mott A Oakhill

Correspondence to: Dr F A Bu'Lock, Department of Paediatric Cardiology, Alder Hey Children's Hospital, Eaton Road, Liverpool L12 2AP.

Accepted 6 June 1996 myocytes, ${ }^{2-4}$ probably mediated by toxic free radicals generated by an intracellular ironanthracycline complex. ${ }^{56}$ Cardiac irradiation, incurred during thoracic, craniospinal, or total body radiotherapy will also cause significant cardiac damage, which is exacerbated by concomitant anthracycline treatment. ${ }^{78}$ High dose cyclophosphamide ${ }^{910}$ and mitozantron $\mathrm{e}^{112}$ also cause cardiac injury.

A number of ways to reduce cardiotoxicity have been suggested but the use of less toxic anthracyclines, ${ }^{1314}$ prolonged infusion schedules, ${ }^{15}{ }^{16}$ or adjuvant cardioprotective agents, ${ }^{17} 18$ although increasingly advocated, are not yet of proved utility. Meanwhile, further attempts to improve rates of cure using 'megatherapy' may succeed only at the expense of an increase in the incidence of anthracycline cardiomyopathy.

Clinical evidence of anthracycline cardiotoxicity-congestive cardiac failure-is only manifest very late. By this stage, histological myocardial damage is severe, all physiological compensatory mechanisms have failed, and the prognosis is very poor indeed. ${ }^{361920}$ Histological monitoring of subclinical cardiac damage is possible using electron microscopic assessment of serial endomyocardial biopsy specimens, ${ }^{2122}$ but this is both invasive and highly resource intensive. Thus it is rarely applicable in clinical practice and measures of left ventricular function are generally used as less invasive surrogate markers of subclinical myocardial damage. Overall left ventricular ejection function can be assessed using radionuclide angiography ${ }^{2324}$ or echocardiography 2526 and some groups have advocated indices related to 'myocyte contractility', which may also be obtained echocardiographically. ${ }^{27} 28$ Measurement of transverse left ventricular systolic shortening fraction from the $M$ mode echocardiogram is probably the most widely used method. Although, like all noninvasive techniques, the use of shortening fraction does have some limitations, it has been well validated as a surrogate index of anthracycline cardiotoxicity by many groups.

The majority of studies reporting the effects of anthracyclines on left ventricular function have been cross sectional and have generally concentrated on status after treatment. However, most report a relationship between decline in left ventricular function and increasing anthracycline dose, although with the marked individual variability in dose sensitivity also noted in both clinical ${ }^{329}$ and histopathological ${ }^{3132}$ studies. It is this individual variability that imposes limits on the efficacy of uniform dose restriction in preventing anthracycline cardiomyopathy. However, if also manifest during treatment, it offers the possibility for early identification of susceptibility to cardiotoxicity to allow modification of subse- 
quent treatment in the particularly 'at risk'patient.

The results of a detailed prospective study of left ventricular function in children receiving anthracycline treatment were therefore examined to determine whether the variation in susceptibility to anthracycline cardiotoxicity could be detected using left ventricular shortening fraction. If so, it was hoped to determine criteria that might be used for individual tailoring of antitumour treatment on the basis of both oncological and cardiac status.

\section{Subjects and methods}

Between August 1989 and July 1992, all children treated in our unit with chemotherapy regimens including anthracyclines participated in a prospective cardiotoxicity study. All patients underwent detailed cardiovascular and echocardiographic examinations before first 'on study' anthracycline treatment and shortly before each subsequent anthracycline treatment, as well as one month after the last treatment.

Height and weight were measured on each occasion and body surface area (BSA, in $\mathrm{m}^{2}$ ) calculated from standard nomograms. Blood pressure was recorded in $\mathrm{mm} \mathrm{Hg}$ and any abnormal cardiovascular symptoms or signs were noted. Blood haemoglobin concentration was $>80 \mathrm{~g} / 1$ on all occasions. All echocardiographic examinations were performed and analysed by a single experienced operator (FAB).

Left ventricular systolic function was assessed by conventional steered $M$ mode echocardiography from the parasternal long axis view using a Hewlett Packard 77020AC ultrasound scanner with simultaneous electrocardiographic recording. Left ventricular diastolic diameter (LVDD) and posterior wall diastolic thickness were measured at the point of maximum diastolic posterior deflection of the posterior wall. Left ventricular systolic diameter (LVDS) and posterior wall systolic thickness were measured at the point of maximum anterior deflection of the posterior wall. The mean of measurements from four cardiac cycles were used and left ventricular shortening fraction (\%) was calculated from the mean left ventricular dimensions as:

Shortening fraction $=\frac{(\text { LVDD }- \text { LVDS })}{\text { LVDD }} \times 100$.

\section{STUDY GROUP}

During the study period, 138 children underwent a total of 651 serial cardiovascular and echocardiographic examinations during anthracycline chemotherapy for a variety of haematological and solid malignancies. Anthracyclines were administered by slow bolus injection in increments of $35-100 \mathrm{mg} / \mathrm{m}^{2}$ and four patients also received cardiac irradiation. Where patients received additional cardiotoxic but non-anthracycline treatment, subsequent examination details have not been included.

Studies were stratified by cumulative anthracycline dose into nine groups: pretreatment, $1-100 \mathrm{mg} / \mathrm{m}^{2}, 101-200 \mathrm{mg} / \mathrm{m}^{2}$, etc up to 700 $\mathrm{mg} / \mathrm{m}^{2}$, and $>700 \mathrm{mg} / \mathrm{m}^{2}$. Equipotency for cardiotoxicity was assumed for all three types of anthracycline (see below). Where more than one study per patient fell within a single dose group, only the study performed at the highest dose was used for analysis.

Data from 13 patients were completely excluded by reason of death during induction treatment $(n=3)$, experimental cardioprotection $(n=4)$, structural cardiac abnormalities $(n=2)$, technical difficulties $(n=1)$, or serial studies only within the same $100 \mathrm{mg} / \mathrm{m}^{2}$ dose range $(n=3)$.

After data stratification, a total of 451 serial echocardiograms performed during treatment of 125 children for malignant disease were used for analysis. There were 66 boys and 59 girls, with BSAs between 0.34 and 2.08 (median 0.8$) \mathrm{m}^{2}$. They were aged between 0.5 and 20 (median 6.3) years at first study and received cumulative anthracycline doses between 45 and 1150 (mean 320, median 270) $\mathrm{mg} / \mathrm{m}^{2}$. Ninety two patients were studied before receiving any anthracycline, 33 had received prior anthracyclines and their data series started at doses between 70 and 600 (median 150) $\mathrm{mg} / \mathrm{m}^{2}$.

\section{CONTROL DATA}

Study data were compared with those obtained from 137 healthy children and young adults examined by identical techniques, expressed as group median values for $0.2 \mathrm{~m}^{2}$ BSA intervals. ${ }^{33} 34$ Matched median normal control values of all study parameters were determined for each patient on the basis of their BSA at first examination and were used for paired comparisons as described previously elsewhere. ${ }^{34}$

In our control studies fractional shortening was found to be independent of body size or age. The normal values were $38 \%$ for the 50 th centile, $35 \%$ for the 25 th, and $34 \%$ for the 10 th. No normal subject had a shortening fraction $<30 \%$. Thus for the purposes of this study, a shortening fraction $\geqslant 35 \%$ was considered unequivocally normal, 30-34\% 'borderline', and $<30 \%$ was defined as abnormal.

ETHICAL ASPECTS

Full ethical approval was given for the study by the Bristol and Weston district ethical committee. Informed consent was obtained from all parents and from the patients themselves where appropriate.

\section{Results}

CLINICAL COURSE

Six children developed cardiac failure related to their chemotherapy, from which three died despite vigorous antifailure treatment. Four of these decompensated after anthracycline treatment alone (cumulative doses $270,686,705$, and $1000 \mathrm{mg} / \mathrm{m}^{2}$ ) while two developed congestive cardiac failure associated with subsequent antitumour treatment. One of these patients died from cardiogenic shock after $50 \mathrm{mg} / \mathrm{m}^{2}$ of mitozantrone (after $300 \mathrm{mg} / \mathrm{m}^{2}$ of daunorubicin) while the other developed congestive cardiac failure after bone marrow transplanta- 
Table 1 Changes in median values of parameters of left ventricular systolic function with increasing anthracycline dose

\begin{tabular}{|c|c|c|c|c|c|c|c|c|c|c|c|}
\hline & \multirow{2}{*}{$\begin{array}{l}\text { Patient }(P) \text { or } \\
\text { control }(C) \text { data }\end{array}$} & \multicolumn{9}{|c|}{ Dose group } & \multirow[b]{2}{*}{ END } \\
\hline & & 0 & 1 & 2 & 3 & 4 & 5 & 6 & 7 & 8 & \\
\hline Dose $\left(\mathrm{mg} / \mathrm{m}^{2}\right)$ & $P$ & 0 & 90 & 180 & 285 & 385 & 483 & 573 & 686 & 857 & 270 \\
\hline \multirow{2}{*}{ Age (years) } & $\mathbf{P}$ & 6.31 & 7.38 & 7.27 & 7.95 & 8.08 & 9.29 & 7.87 & 8.09 & 8.48 & 7.58 \\
\hline & C & 5.5 & 5.5 & 5.5 & 5.5 & 5.5 & 8.01 & 8.01 & 5.5 & 5.5 & 5.5 \\
\hline \multirow[t]{2}{*}{$\operatorname{BSA}\left(\mathrm{m}^{2}\right)$} & $\mathrm{P}$ & 0.81 & 0.85 & 0.85 & 0.94 & 0.90 & 0.99 & 0.98 & 0.94 & 1.0 & 0.88 \\
\hline & C & 0.78 & 0.78 & 0.78 & 0.78 & 0.78 & 1.02 & 1.02 & 0.78 & 0.78 & 0.78 \\
\hline \multirow[t]{2}{*}{ BPS (mm Hg) } & $\mathbf{P}$ & 110 & 110 & 100 & 100 & 105 & 100 & 100 & 85 & 90 & 100 \\
\hline & C & 95 & 95 & 95 & 95 & 95 & 95 & 95 & 95 & 95 & 95 \\
\hline \multirow[t]{2}{*}{$\mathrm{BPD}(\mathrm{mm} \mathrm{Hg})$} & $P$ & 70 & 67 & 60 & 65 & 60 & 60 & 60 & 60 & 60 & 60 \\
\hline & $\mathrm{C}$ & 63 & 63 & 63 & 63 & 63 & 63 & 64 & 63 & 63 & 63 \\
\hline \multirow[t]{2}{*}{ LVDD (cm) } & $\mathrm{P}$ & 3.64 & 3.66 & 3.73 & 3.80 & 3.82 & 3.88 & 3.78 & 3.81 & 4.26 & 3.80 \\
\hline & C & 3.63 & 3.63 & 3.63 & 3.63 & 3.63 & 3.91 & 3.91 & 3.63 & 3.63 & 3.63 \\
\hline \multirow[t]{2}{*}{ LVDS (cm) } & $P$ & 2.34 & 2.37 & 2.40 & 2.46 & 2.52 & 2.58 & 2.58 & 2.66 & 3.19 & 2.46 \\
\hline & C & 2.29 & 2.29 & 2.29 & 2.29 & 2.29 & 2.47 & 2.47 & 2.29 & 2.29 & 2.29 \\
\hline \multirow[t]{2}{*}{ SF (\%) } & $P$ & 38 & 36 & 36 & 34 & 33 & 33 & 32 & 29 & 27 & 34 \\
\hline & $\mathrm{C}$ & 38 & 38 & 38 & 38 & 38 & 38 & 38 & 38 & 38 & 38 \\
\hline \multirow[t]{2}{*}{ PWD (cm) } & $\mathrm{P}$ & 0.06 & 0.63 & 0.60 & 0.64 & 0.65 & 0.63 & 0.66 & 0.60 & 0.65 & 0.62 \\
\hline & $\mathrm{C}$ & 0.56 & 0.56 & 0.56 & 0.56 & 0.56 & 0.60 & 0.60 & 0.56 & 0.56 & 0.56 \\
\hline \multirow[t]{2}{*}{ PWS (cm) } & $\mathbf{P}$ & 0.97 & 1.0 & 0.95 & 1.0 & 0.97 & 1.05 & .98 & 0.89 & 0.92 & 0.96 \\
\hline & $\mathrm{C}$ & 0.92 & 0.92 & 0.92 & 0.92 & 0.92 & 1.03 & 1.03 & 0.92 & 0.92 & 0.92 \\
\hline$\%$ with $\mathrm{SF}<30 \%$ & & 3 & 5.6 & 6.9 & 18 & 14 & 23 & 20 & 60 & 75 & 19 \\
\hline No & $P$ & 92 & 89 & 102 & 76 & 43 & 30 & 10 & 5 & 4 & 125 \\
\hline
\end{tabular}

$\mathrm{BSA}=$ body surface area; $\mathrm{BPD}=$ diastolic blood pressure; $\mathrm{BPS}=$ systolic blood pressure; $\mathrm{END}=$ median data from all patients at end of treatment study; $\mathrm{LVDD}=$ left ventricular diastolic diameter, measured at the point of maximum diastolic posterior displacement of the posterior wall; LVDS=left ventricular systolic diameter; PWD=diastolic left ventricular posterior wall thickness; PWS=systolic left ventricular posterior wall thickness; $S F=$ left ventricular shortening fraction.

Bold figures indicates a difference between patients and controls with $\mathrm{p}<0.05$.

NB: Complete numerical data are available from the authors on request.

tion using high dose cyclophosphamide $(120$ $\mathrm{mg} / \mathrm{kg}$ ) and total body irradiation (after 470 $\mathrm{mg} / \mathrm{m}^{2}$ of anthracyclines).

FUNCTIONAL COURSE (SEE TABLE 1)

Left ventricular function deteriorated during treatment in the majority of patients.

Fractional shortening was generally normal $(\geqslant 30 \%)$ before starting treatment (in three patients shortening fraction was marginally subnormal at $28 \%$ ), and there were no significant differences in left ventricular cavity dimensions from control values (two tailed $\mathrm{p}>0.05$, Wilcoxon's signed ranks tests). However, both systolic and diastolic posterior wall thickness were increased relative to control values at pretreatment study (see table 1), and

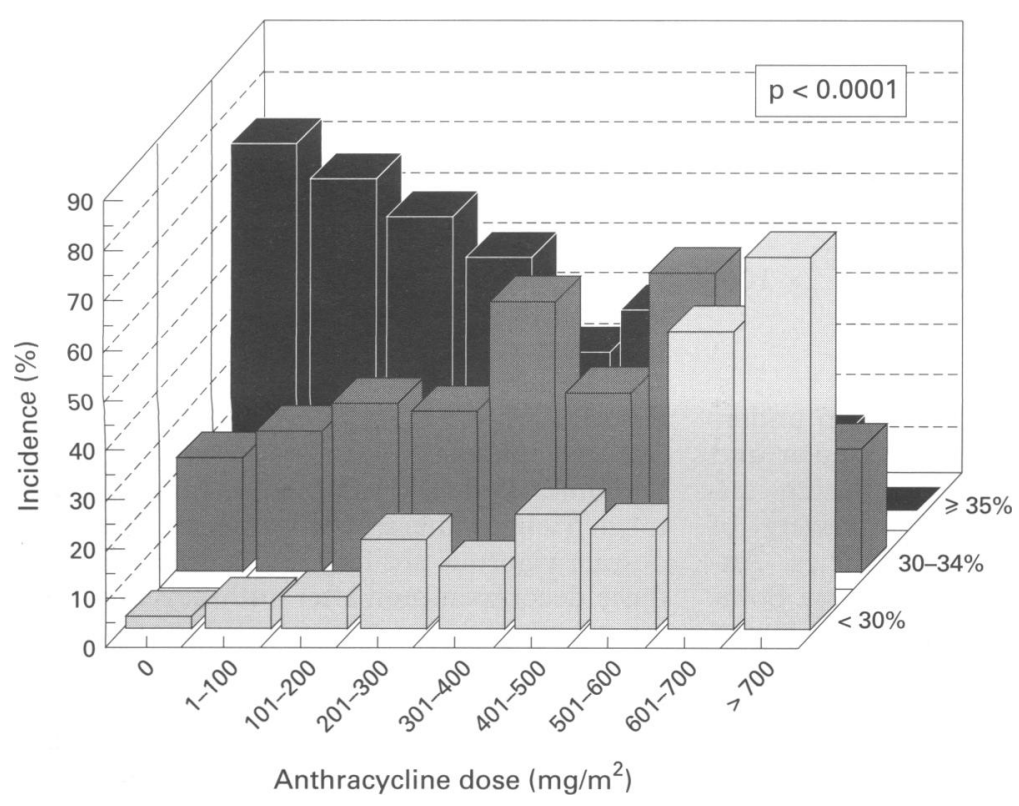

Figure 1 Histogram showing the increasing incidence of abnormal shortening fraction $(<30 \%)$ and decreasing incidence of normal shortening fraction $(\geqslant 35 \%)$ with increasing cumulative anthracycline dose. These changes are highly significant on $\chi^{2}$ analysis. both systolic and diastolic blood pressure were also greater than control levels.

Overall, fractional shortening fell with increasing cumulative anthracycline dose, although absolute changes varied in individual patients. Simple linear regression analysis (least squares) revealed an average absolute fall in shortening fraction of $1 \%$ per $100 \mathrm{mg} / \mathrm{m}^{2}$ (Pearson's correlation coefficient $(R)=-0.29$, $\mathrm{p}<0.0001)$. In addition, the incidence of shortening fraction $<30 \%$ increased with cumulative dose (from 3\% (three patients at $28 \%$ ) pretreatment) to $75 \%$ of patients receiving $>700 \mathrm{mg} / \mathrm{m}^{2}$ ) and the proportion of patients with normal shortening fraction fell (see fig 1 , $\left(\mathrm{p}<0.001, \chi^{2}\right.$ test $)$ ).

Both systolic and diastolic left ventricular dimensions generally increased during treatment. However, the increase in systolic left ventricular diameter with escalating dose was much greater than that for diastole, so fractional shortening proportionately decreased. Systolic diameter was significantly greater, and shortening fraction lower than control values even after doses of $100 \mathrm{mg} / \mathrm{m}^{2}$ or less. Differences from control in diastolic diameter were apparent at doses $>100 \mathrm{mg} / \mathrm{m}^{2}$.

Although posterior wall thickness was already raised pretreatment, there was a further increase (particularly in diastolic wall thickness) with the first anthracycline treatment. Diastolic wall thickness then decreased but remained greater than control even at the highest doses. Systolic posterior wall thickness also remained raised throughout treatment, although it possibly decreased somewhat at the highest doses and was little different from control at the end of treatment $(p=0.09)$.

Both systolic and diastolic blood pressure also fell during the treatment period. The fall was most marked early on, such that diastolic blood pressure was similar to control values by $200 \mathrm{mg} / \mathrm{m}^{2}$, although systolic blood pressure 


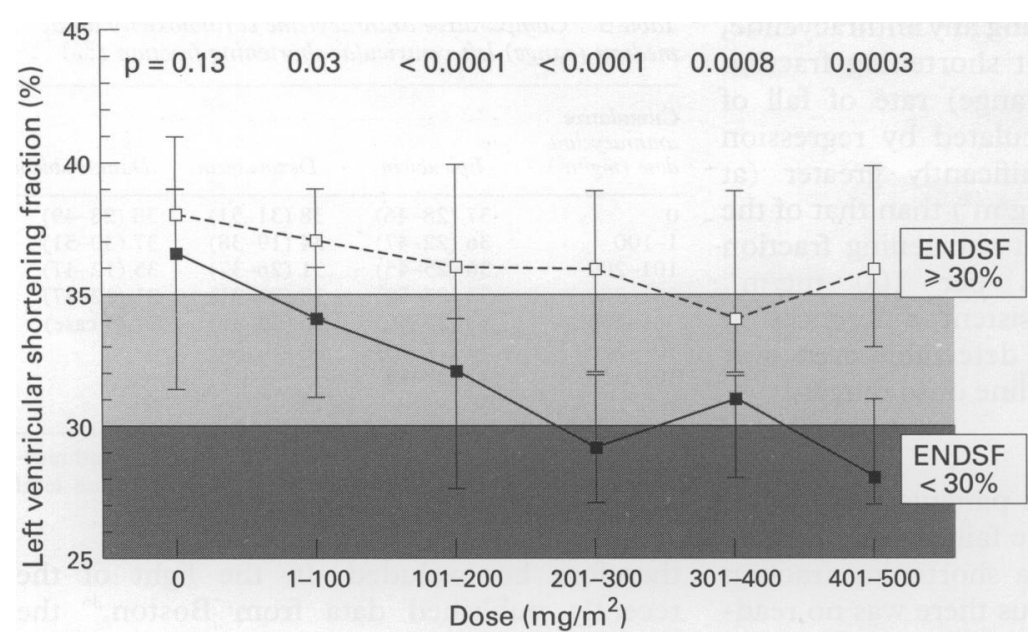

Figure 2 Shows median and interquartile range (error bars) values for left ventricular shortening fraction with increasing anthracycline dose, subdivided on the basis of end of treatment shortening fraction ( $E N D S F \geqslant 30 \%, n=101$, and $E N D S F<30 \%, n=24$ ). The $p$ values are for Mann-Whitney $U$ tests performed between the groups. Shortening fraction $<30 \%$ is considered abnormal, $30-34 \%$ is 'borderline', and $\geqslant 35 \%$ is normal.

remained mildly raised throughout treatment. No patient required antihypertensive medication.

RELATIONSHIP BETWEEN SYMPTOMATIC ANTHRACYCLINE CARDIOMYOPATHY AND FRACTIONAL SHORTENING

Of the four patients who developed cardiac failure directly attributable to anthracycline treatment, two (with shortening fractions of 12 and $19 \%$, one of whom died in uncontrollable heart failure) had overt cardiomyopathy at the time of the scan. In the other two (shortening fractions 19 and $27 \%$ at the end of treatment) cardiac decompensation occurred within the next two months without further cardiotoxic treatment but was controlled with antifailure medication. All six patients who developed cardiac failure died within six months of last study; three from cardiac failure and three from recurrent malignant disease, with cardiac failure controlled on medication. No child with a shortening fraction $<20 \%$ at any stage remained without symptomatic cardiac failure. Eighteen patients had a shortening fraction $<30 \%$ at some stage but so far have remained asymptomatic from a cardiac viewpoint. However, nine of these patients $(50 \%)$ died within six months of last study, from recurrent malignancy or from sepsis, and it is possible that in some the development of cardiac failure was pre-empted by death from other causes.

Table 2 Rate of change of left ventricular shortening fraction (SF), subdivided by end of treatment shortening fraction

\begin{tabular}{llll}
\hline Parameter & Final SF<30\% & Final $S F \geqslant 30 \%$ & p Values \\
\hline Fall in SF per $100 \mathrm{mg} / \mathrm{m}^{2}$ (\%) (individual slope) & & & \\
Median & 2.0 & 1.0 & 0.009 \\
Range & -0.5 to 12.0 & -8.0 to 13.0 & \\
Interquartile range & 1.0 to 3.0 & -0.6 to 3.0 & \\
No & 24 & 101 & \\
Fall in SF per $100 \mathrm{mg} / \mathrm{m}^{2}(\%)$ & & & 0.006 \\
$\quad$ (overall, patients first studied pretreatment) & & & \\
Median & 2.0 & 0.4 & \\
Range & 0.2 to 5.0 & -13 to 13 & \\
Interquartile range & 1.2 to 3.2 & -0.9 to 2.4 & \\
No & 16 & 76 & \\
\hline
\end{tabular}

END OF TREATMENT SHORTENING FRACTION

Twenty four (19\%) patients had a shortening fraction $<30 \%$ by the end of treatment, of whom six had treatment stopped or modified because of a shortening fraction $<30 \%$, three with incipient heart failure. When data from patients with end of treatment shortening fraction $<30 \%$ were compared with those with end of treatment shortening fraction $\geqslant 30 \%$, important differences in response to anthracyclines earlier in treatment were apparent:

\section{Absolute values of shortening fraction}

Pretreatment fractional shortening values were similar in both subgroups $(<30 \% v \geqslant 30 \%$, Mann-Whitney U test), but median and interquartile range values of shortening fraction diverged at very low anthracycline doses (see fig 2). After the first dose of anthracycline a marked difference between the groups was apparent. This discrepancy increased further at higher doses such that after $200 \mathrm{mg} / \mathrm{m}^{2}$ the interquartile ranges no longer overlapped, meeting at $32 \%$. The difference in shortening fraction was accompanied by differences in systolic but not diastolic left ventricular diameter, but there were no significant differences in posterior wall thickness between the groups.

\section{Rate of fall of shortening fraction}

While individual absolute values of shortening fraction early in treatment may therefore provide useful information on adverse cardiac response to anthracycline treatment, there may still be concerns for patients with shortening fraction within the 'borderline' normal range (30-34\%). It would be helpful to identify which simply reflect a continuation of low normal values (two of the three patients with pretreatment shortening fraction $=28 \%$ finished treatment with shortening fraction $\geqslant 30 \%$ ) and which represent a steeply falling shortening fraction from higher values. The slope of the fall in shortening fraction (regression line) was therefore calculated individually from all data points for each patient. Since patients studied over smaller dose ranges had fewer studies a wide range of individual regression slope values (see table 2) was obtained, with the outliers largely representing the patients with the fewest studies. Nevertheless, the slope of shortening fraction against cumulative anthracycline dose was significantly greater in those with shortening fraction $<30 \%$ compared with those with shortening fraction $\geqslant 30 \%$ at end of treatment.

The median fall in shortening fraction per $100 \mathrm{mg} / \mathrm{m}^{2}$, calculated by regression analysis, was also remarkably similar to the overall fall per $100 \mathrm{mg} / \mathrm{m}^{2}$ calculated from before and end of treatment shortening fractions in the 92 patients first studied before receiving any anthracycline (see table 2). These two measurements also showed reasonable good correlation on an individual basis (regression line through the origin, slope $=0.25, R=0.65$, $\mathrm{p}<0.0001$ ), suggesting that the rate of fall in shortening fraction is relatively constant throughout treatment. Of the 78 patients who received a total dose $\leqslant 300 \mathrm{mg} / \mathrm{m}^{2}$ and were 
first studied before receiving any anthracycline, $11 \mathrm{had}$ end of treatment shortening fraction $<30 \%$. Their median (range) rate of fall of shortening fraction (calculated by regression analyses) was also significantly greater (at $3(0.7$ to 12$) \%$ per $\left.100 \mathrm{mg} / \mathrm{m}^{2}\right)$ than that of the 57 with end of treatment shortening fraction $\geqslant 30 \% \quad\left(1(-8\right.$ to 12$) \%$ per $100 \mathrm{mg} / \mathrm{m}^{2}$, $\mathrm{p}=0.006)$. Thus, consistent differences in functional behaviour are detectable even over relatively small anthracycline dose ranges.

GENDER

Although four of the six patients who developed symptomatic cardiac failure were female, of the 24 patients with a shortening fraction $<30 \%, 12$ were male. Thus there was no,readily apparent gender predisposition for the development of left ventricular dysfunction during or soon after anthracycline treatment.

ANTHRACYCLINE TYPE

In order to maximise the numbers of patients available for analyses, the three anthracycline types used in these patients were treated as equipotent for cardiotoxicity. It was therefore necessary to examine the validity of this assumption and to determine whether variation in functional outcome could be attributed to any differential cardiotoxicity of the anthracycline agents used.

Thirty patients received epirubicin alone (median (range) dose $535(270-1150) \mathrm{mg} / \mathrm{m}^{2}$ ), 13 doxorubicin $\left(285(250-445) \mathrm{mg} / \mathrm{m}^{2}\right)$, and 59 only daunorubicin $\left(270(180-300) \mathrm{mg} / \mathrm{m}^{2}\right)$. Sixteen had received epirubicin after either doxorubicin $(n=3)$ or daunorubicin $(n=13)$ and three had received both daunorubicin and doxorubicin. The four children who received cardiac irradiation had all received doxorubicin.

There were no differences in the incidence of symptomatic dysfunction between anthracycline types, although numbers were necessarily small (see table 3). Similarly, on a 'dose for dose' basis, there were no significant $(p \leqslant 0.05$, Mann-Whitney $U$ test) differences in absolute shortening fraction between the different anthracycline types at any dose.

\section{Discussion}

Anthracycline chemotherapy causes myocardial damage leading to acute congestive cardiac failure during or soon after treatment in a significant percentage of patients treated, depending on the total cumulative doses used..$^{35}$ The $3 \%$ incidence of early cardiac failure in this study, rising to $5 \%$ after the use of additional cardiotoxic agents is consistent with other reports. ${ }^{1935}$ A further $19 \%$ of study patients completed chemotherapy with significant abnormalities of systolic left ventricular function (shortening fraction $<30 \%$ ).

No evidence was found for any major differences in cardiotoxic potency between the three anthracycline types used in this study. However, daunorubicin and doxorubicin were not generally administered in such high doses as those used with epirubicin and clinically important differences at higher doses cannot
Table 3 Comparative anthracycline cardiotoxicity data; median (range) left ventricular shortening fraction (\%)

\begin{tabular}{llll}
\hline $\begin{array}{l}\text { Cumulative } \\
\text { anthracycline } \\
\text { dose }\left(m g / m^{2}\right)\end{array}$ & Epirubicin & Doxorubicin & Daunorubicin \\
\hline 0 & $37(28-46)$ & $38(31-51)$ & $38(28-49)$ \\
$1-100$ & $36(22-47)$ & $34(19-38)$ & $37(30-51)$ \\
$101-200$ & $36(25-45)$ & $31(26-37)$ & $35(12-47)$ \\
$201-300$ & $33(27-50)$ & $30(29-31)$ & $31(12-47)$ \\
$301-400$ & $33(27-50)$ & $30(29-31)$ & $31(1$ case) \\
$401-500$ & $34(27-43)$ & $27(1$ case) & - \\
$501-600$ & $32(27-44)$ & - & - \\
No & 30 & 13 & 59 \\
\hline
\end{tabular}

NB: No significant differences $(p<0.05)$ between any anthracycline type on 'dose for dose' comparisons at any dose level (Mann-Whitney U test).

therefore be excluded. In the light of the recently published data from Boston, ${ }^{36}$ the absence of gender related sensitivity to cardiotoxicity during treatment is noteworthy. However, in this serial study, multivariate analysis of data was not undertaken and subtle differences are not therefore excluded. Alternatively, gender related differences may actually be a function of differential myocardial growth and development and thus may only be manifest at long term follow up, although we have not noted this in our own long term survivors. ${ }^{34}$

The lack of appreciable myocardial thinning during treatment is of considerable interest since it is very pronounced at late follow up, ${ }^{2834}$ and has been shown to increase with time from treatment. ${ }^{34}$ The relative myocardial hypertrophy noted in the pretreatment patients probably reflects a variety of factors such as prolonged anaemia, relative hypertension, neurohumoral responses, and myocardial infiltration. During treatment, steroids are used in some chemotherapy regimens, which may explain the persistence of increased systolic blood pressure and wall thickness found in some patients. However, it is also possible that the maintenance of normal wall thickness despite myocyte loss during treatment reflects the myocyte swelling and sarcoplasmic vacuolation associated with anthracycline treatment. ${ }^{21}$ Since Lipshultz et al noted that the abnormalities of left ventricular end systolic wall stress detected in their late follow up study were largely associated with wall thinning, ${ }^{28}$ the use of such complex techniques during treatment is likely to add little to the information gained from simple clinical and $M$ mode assessment of cardiac function.

In view of the small numbers of patients with overt cardiac failure and high early mortality rate for the group with a shortening fraction $<30 \%$ ( $50 \%$ of the 18 asymptomatic patients with end of treatment shortening fraction $<30 \%, 58 \%$ of all patients with shortening fraction $<30 \%$ ), it was not possible to establish any meaningful statistical relationship between shortening fraction during treatment and the occurrence of cardiac failure. However the association between reduced fractional shortening and overt anthracycline cardiomyopathy clearly justifies the use of shortening fraction as an index of lesser degrees of myocardial damage in this study group. This is further supported by the significant inverse relationship demonstrated in this study between 
cumulative anthracycline dose and left ventricular shortening fraction. The marked individual variability in the rate of fall of fractional shortening with increasing anthracycline dose is consistent with other studies. ${ }^{329-32}$ It is therefore highly noteworthy that each individual's behaviour appears to be relatively consistent throughout treatment and has a clear relationship to the functional status at the end of anthracycline treatment. Thus, the use of a combination of measurement of the rate of fall of shortening fraction and of individual absolute values of fractional shortening at low anthracycline doses, should allow identification of patients particularly susceptible to anthracycline cardiotoxicity early on in treatment. However, these results are drawn from a retrospective analysis of prospectively acquired data and would benefit from further prospective validation.

The most disturbing aspects of anthracycline induced cardiac damage are the long term impairment of cardiac function and the increasing incidence of late decompensation which have only recently become apparent. ${ }^{28} 34$ It appears that after an initial 'honeymoon period', ${ }^{38}$ in which surviving myocytes are able to compensate for the acute myocyte loss by hypertrophic changes (fractional shortening may even return to near normal values), there is a continuing myocardial attenuation, probably due both to failure of further myocyte growth and gradual loss of 'overworked' residual myocytes. Our own studies and those of other groups have now demonstrated that myocardial thickness and function deteriorate with time after anthracycline treatment, ${ }^{283437}$ with more than $40 \%$ of patients showing significant abnormalities of cardiac function $\geqslant 15$ years after anthracycline treatment. ${ }^{40}$ Since Steinherz et al have also demonstrated a clear relationship between end of treatment cardiac status/shortening fraction and likelihood of late decompensation, ${ }^{37}$ the ability to predict likely functional outcome early in treatment becomes even more crucial.

There has been considerable discussion about both the value and timing of monitoring for anthracycline cardiotoxicity. ${ }^{23-2630}$ 41 The guidelines suggested by the Children's Cancer Study Group were based on a large experience at the Memorial Sloan Kettering Cancer Center and on previously reported studies. ${ }^{42}$ These guidelines have been criticised by Lipshultz et $a l^{43}$ as being both unproved and as having potential negative consequences for antitumour treatment. The present 'on treatment' study is the first to identify a number of potential pointers to each individual's susceptibility to anthracycline cardiotoxicity, which can be applied throughout treatment. It is not suggested that these criteria be used to define rigid limits for cessation of anthracycline treatment, but rather to provide the basis for informed consideration of the risks and benefits of continuation of anthracycline treatment in any given oncological situation. Overt cardiac failure is an absolute contraindication to continuation of anthracycline treatment; lesser degrees of myocardial dysfunction or increased sensitivity to cardiotoxicity may warrant either dose reduction or early cessation of treatment. Where the risk that treatment modification may significantly jeopardise antitumour success is substantial, an informed decision to continue anthracyclines may be justified. In less susceptible patients, the beneficial use of higher than usual doses of anthracycline may be facilitated and the standard recommended maximum doses perhaps need no longer apply. As cardioprotective agents become available, ${ }^{1718}$ identification of those patients most susceptible to cardiotoxicity might provide a rational basis for their selective use.

\section{Conclusions}

Regular monitoring of left ventricular shortening fraction early during anthracycline treatment can identify those patients at higher risk of subsequent cardiotoxicity. Patients with fractional shortening $<30 \%$ at any stage, $<32 \%$ at $>200 \mathrm{mg} / \mathrm{m}^{2}$, or those with a fall in shortening fraction of $>2-3$ absolute $\%$ per $100 \mathrm{mg} / \mathrm{m}^{2}$ would appear to be at increased risk of significant cardiotoxicity. Modification of treatment should be considered for these patients in the light of each individual's tumour status.

The echocardiographic determination of individual susceptibility to anthracycline cardiotoxicity requires pretreatment and frequent low dose studies, and a meticulous and uniform echocardiographic technique. Such monitoring has significant resource implications. Further prospective studies of the clinical value and cost effectiveness of on treatment monitoring are now indicated, using the criteria determined in this study.

FAB was supported by the Cancer Research Campaign, MGM is professor of paediatric oncology and is supported by the Cancer and Leukaemia in Childhood Trust.

1 Mott MG. Neoplasia in childhood: 25 years of progress Ann Oncol 1995 (in press)

2 Young RC, Ozols RF, Myers CE. The anthracycline anti-neoplastic drugs. N Engl f Med 1981;305:139-53.

3 Praga C, Beretta G, Vigo PL, et al. Adriamycin cardiotoxicity: a survey of 1273 patients. Cancer Treat Rep 1979;63:827-34.

4 Myers CE, McGuire WP, Liss RH, et al. Adriamycin; the role of lipid peroxidation in cardiac toxicity and tumour response. Science 1977;197:165-7.

5 Doroshow JH, Reeves J. Anthracycline enhanced oxygen radical formation in the heart. Proceedings of the American Association For Cancer Research 1980;21:266(abstr).

6 Lefrak E, Pitha J, Rosenheim S, Gottlieb JA. A clinicopathologic analysis of Adriamycin cardiotoxicity. Cancer 1973;32: 302-14.

7 Billingham ME, Bristow MR, Glatstein E, et al. Adriamycin cardiotoxicity, endomyocardial biopsy evidence of encardiotoxicity, endomyocardial biopsy evidence of en-

8 Fajardo LF, Eltringham JR, Stewart JR. Combined cardioFajardo LF, Eltringham JR, Stewart JR. Combined cardio-
toxicity of adriamycin and X-radiation. Lab Invest 1976;34: 86-96.

9 Mills BA, Roberts RW.Cyclophosphamide induced cardiomyopathy: a report of two cases and a review of the English literature. Cancer 1979;43:2223-6.

10 Braverman AC, Antin JH, Plallert MT, Cook EF, Lee RT. Cyclophosphamide cardiotoxicity in bone-marrow transplantation: a prospective evaluation of new dosing regimens. $₹$ Clin Oncol 1991;9:1215-23.

11 Unverferth DV, Unverferth BJ, Balcerzak SP, Bashore TA, Neidhart JA. Cardiac evaluation of mitoxantrone. Cancer Treat Rep 1983;67:343-50.

12 Pratt CB, Crom DB, Wallenberg J, et al. Fatal congestive heart failure following mitoxantrone therapy in two heart failure following mitoxantrone therapy in two
children previously treated with doxorubicin and cisplatin. Cancer Treat Rep 1983;67:85-8.

13 Nielsen D, Jensen JB, Dombernowsky $P$, et al. Epirubicin cardiotoxicity: a study of 135 patients with advanced brast cardiotoxicity: a study of 135 patients 
14 Bonnadonna G, Gianni L, Santoro A, et al. Drugs ten years later: epirubicin. Ann Oncol 1993;4:359-69.

15 Legha SS, Benjamin RS, Mackay B, et al. Reduction of doxorubicin cardiotoxicity by prolonged continuous intravenous infusion. Ann Intern Med 1982;96:133-9.

16 Casper ES, Gaynor JJ, Hajdu SI, et al. A prospective randomised trial of adjuvant chemotherapy with bolus versus continuous infusion of doxorubicin in patients with high grade extremity soft tissue sarcoma: an analysis of prognostic factors. Cancer 1991;68:1221-9.

17 Speyer IL, Green MD, Zeleniuch-Jaquotte A, et al. ICRF permits longer treatment with doxorubicin in women with permits longer treatment with doxorubicin

18 Bu'Lock FA, Gabriel HM, Oakhill A, Mott MG, Martin RP. Cardioprotection by ICRF187 against high dose anthracy-
cline toxicity in children with malignant disease. Br Heart $\mathcal{f}$ cline toxicity in

19 Von Hoff DD, Rozencweig M, Layard MW, Slavik M, Muggia FM. Daunomycin-induced cardiomyopathy in children and adults. $A m \mathcal{F}$ Med 1977;62:200-8.

20 Dearth J, Osborn R, Wilson E, et al. Anthracycline-induced cardiomyopathy in children. A report of six cases. Med Pediatr Oncol 1984;12:54-8.

21 Billingham ME, Mason JW, Bristow MR, Daniels JR. Anthracycline cardiomyopathy monitored by morphologic changes. Cancer Treat Rep 1978;62:865-72.

22 Torti FM, Bristow MM, Lum BL, et al. Cardiotoxicity of epirubicin and doxorubicin: assessment by endomyocardial biopsy. Cancer Res 1986;46:3722-7.

23 Palmeri ST, Bonow RO, Myers CE, et al. Prospective evaluation of doxorubicin cardiotoxicity by rest and exercise

24 Schwartz RG, McKenzie WB, Alexander J, et al. Congestive heart failure and left ventricular dyshortening fractionunction complicating doxorubicin therapy: seven year experience using serial radionuclide angiography. $\mathrm{Am} \mathcal{F}$ Med 1987;82:1109-18.

25 Mott MG, Jordan SC.Cardiotoxicity of adriamycin assessed by echocardiography. Proceedings of the 10th Meeting of Sociëté Internationale Oncologie Pediatrique. Belgium 1978: 188 (abstr).

26 Bloom KR, Bini RM, Williams CM, Sonley MJ, Gribbin MA. Echocardiography in adriamycin cardiotoxicity. Cancer 1978;41:1265-9.

27 Colan SD, Borow KM, Neumann A. Left ventricular end-systolic wall stress-velocity of fiber shortening relation: a load independent index of myocardial contractility. $₹ \mathrm{Am}$ a load independent index of

28 Lipshultz SE, Colan SD, Gelber RD, et al. Late cardiac effects of Adriamycin therapy for childhood acute lymphoblastic leukaemia. $N$ Eng $\mathscr{f}$ Med 1991;324:808-15.
29 Bristow MR, Thompson PD, Martin RP, et al. Early anthracycline cardiotoxicity. Am $\mathcal{F}$ Med 1978;165:823-32

30 Minow RA, Benjamin RS, Lee ET, Gottleib JA. Adriamycin cardiomyopathy: risk factors. Cancer 1977;39:1397-402.

31 Isner JM, Ferrans VJ, Cohen, SR, et al. Clinical and morphological findings after anthracycline chemotherapy. Am $\mathcal{f}$ Cardiol 1983;51:1167-74.

32 Bristow MR, Lopez MB, Mason JW, Billingham ME, Winchester MA. Efficacy and cost of cardiac monitoring in patients receiving doxorubicin. Cancer 1982;50:32-41.

33 Bu'Lock FA, Mott MG, Oakhill A, Martin RP. Left ventricular diastolic function in children measured by Doppler echocardiography: normal values and relation Doppler echocardiography: normal value
with growth. Br Heart $₹$ 1995;73:334-9.

34 Bu'Lock FA, Mott MG, Oakhill A, Martin RP. Left ventricular diastolic function after anthracycline chemotherapy in childhood: relationships with systolic function, symptoms and pathophysiology. Br Heart $\mathcal{F}$ 1995;73:34050.

35 Von Hoff DD, Layard MW, Basa P, et al. Risk factors for doxorubicin-induced congestive heart failure. Ann Intern Med 1979;91:701-17.

36 Lipshultz SE, Lipsitz SR, Mone SM, et al. Female sex and higher drug dose as risk factors for late cardiotoxic effects of doxorubicin therapy for childhood cancer. N Engl f Med 1995;332:1738-43.

37 Steinherz L, Steinherz P, Tan CTC, Heller G, Murphy ML. Cardiac toxicity 4-20 years after completing anthracycline therapy. $¥ A M A 1991 ; 266: 1672-7$.

38 Lewis AB, Crouse VL, Evans W, Takahashi M, Siegel SE. Recovery of left ventricular function after discontinuation of anthracycline chemotherapy in children. Pediatrics 1981; 68:67-72.

39 Saini J, Rich MW, Lyss AP. Reversibility of severe LV dysfunction due to doxorubicin cardiomyopathy; report of three cases. Ann Intern Med 1987;106:814-6.

40 Steinherz LJ, Steinherz PG, Sklar C, Wollner N, Tan C. Cardiac status of 42 patients $\geqslant 15$ years post anthracycline therapy. Med Pediatr Oncol 1994;23:176 (abstr).

41 Mason JW, Bristow MR, Billingham ME, Daniels JR. Invasive and non-invasive methods of assessing Adriamycin cardiotoxic effect in man: superiority of histopathologic assessment using endomyocardial biopsy. Cancer Treat Rep 1978;62:857-64.

42 Steinherz LJ, Graham T, Hurwitz R, et al. Guidelines for cardiac monitoring of children during and after anthracycardiac monitoring of children during and after anthracyCancer Study Group. Pediatrics 1992;89:942-9.

43 Lipshult SE, Sanders SP, Goorin AM, Krischer JP, Sallan SE, Colan SD. Monitoring for anthracycline cardiotoxicity. Pediatrics 1994;93:433-7. 